\begin{tabular}{ll}
\hline INTERNATIONAL RESEARCH JOURNAL OF MULTIDISCIPLINARY TECHNOVATION (IRJMT) \\
MAPLE TREE \\
JOURALS
\end{tabular}

\title{
Smart Safety Helmet for Bike Riders using IoT
}

\author{
P. Dharani ${ }^{1}$, T. Ganesh ${ }^{1}$, V. Gopinath ${ }^{1,}{ }^{*}$, Y. Sharmasth Vali ${ }^{1}$ \\ ${ }^{1}$ Department Computer Science and Engineering, Dhana Lakshmi College of Engineering, Chennai-601 301, Tamil \\ Nadu, India. \\ *Corresponding author E-Mail ID: gopinathviswanathan89@gmail.com
}

DOI: https://doi.org/10.34256/irjmt2044

\begin{abstract}
According to the law of the Indian government as per section 129 of the motor vehicle act of 1988 briefly explains the motorcycle or two-wheeler rider is mandatory to wear the helmet while driving and the recent survey conducted on road accidents by the world health organization (WHO). This WHO organization has briefly mentioned the cause and the prevention of road accidents that are happened around the world. They also mentioned the highest death rate that took place in India and the survey also reported as per the rate 1.5 lakh of road death has been accounted for by each year approximately. The above article motivates us to develop a system that is capable of providing safety and precaution to the bike rider. We designed a system that is capable of detecting the rider is whether wearing the helmet or not. Then detecting if the rider has consumed alcohol or not, whether if these two conditions are yet satisfied then only the motor will ignite or else it will not ignite. In case an accident occurred, our system is capable of detecting the accident and its location approximately. We implanted the led strip indication in the helmet unit to reduce the percentage of an accident during night times.
\end{abstract}

Keywords: Node MCU, Relay driver, MQ-3 sensor, FSR sensor, Vibrating sensor, Limit switches, Helmet.

\section{Introduction}

Nowadays there are many bike accidents occurred in our country and violation of traffic rules by the riders is increasing upon day by day. Most of the accident cases are due to the negligence of wearing the helmet without any special reason and the rider is not aware of traffic rules. There is no proper awareness and the importance of traffic rules and road safety. The official analysis of road accidents by the national crime records bureau's report on road accidental deaths that more than 500 bike accident cases were filed due to drunken driving or rider under the influence of the drug. To reduce these types of accidental cases for the bike rider, we proposed a system which is capable of providing safety, security, and precaution for the bike riders. We named it a smart safety helmet system. The first process of our system is to check whether the bike rider is wearing the helmet or not. If the bike rider is not wearing the helmet, the vehicle will not start. For that, we are using a force-sensing resistor sensor (FSR), which is capable of sensing the presence of the rider. The second process is to find out, whether the bike rider has consumed alcohol or not. If the bike rider is drunken the vehicle will not start, this can be implemented using the MQ-3 alcoholic sensor. The MQ-3 stands for mingan and qi lai, mingan means 'sensitive' and qi lai means 'gas' in Chinese terms. This alcoholic sensor can find out the alcohol presence in the breath of the rider if the permitted range is exceeded then the vehicle will not start. Whether these two conditions satisfy only then the vehicle unit will start or else it will fail to start. The third process is to check whether the vehicle is suspended in an accident or not. For that we are using a 
vibrating sensor also called a piezoelectric sensor. This sensor is used to measure the threshold value of the vibration, which is produced at the impact of an accident occurs to the rider. Once the threshold value is detected then the assigned value, then the message has been sent to the corresponding saved mobile numbers. As the fourth process, we implemented a led strip in the helmet unit, which is cable of lighting the led strips on left, right and brake indication and it can be controlled from a bike unit. This helps bike riders for intimation of presence and directions during night rides.

\section{Existing System}

In the existing system, we can start the bike by the using as a key and we can stop the bike when the rider doesn't wear the helmet. Even though we can't lock the ignition when the rider is drinking mode or during an accident, but we can locate the bike. The helmet is the protective gear to prevent and avoid head injuries in an environment and saves the life of bike riders. This existing idea addresses three main objectives: [1] To ensure the safety of the rider, [2] To the rising modern needs of technological innovations, and [3] To overcome the accident rate. The smart helmet allows vehicle ignition only when the helmet is worn only. An RF Module can be used as a wireless link for communication between transmitter and receiver. The RF module has a frequency that is easy being hacked or interference by other network signals. If the rider is drunk the ignition gets locked and sends a message to the previously saved number with his location. In case of an accident, it will send a message through GSM along with location with the help of the GPS module, but can't find the exact accident spot as accurate. The message sending is not quick and efficient in the existing system.

\section{Disadvantages:}

- The disadvantage of current technology is due to the negligence of riders and the difficulty of implementation of traffic rules by traffic police.

- Riders do not wear a helmet in regions where traffic checking is not done.

- The driver tends to wear a helmet only where they anticipate checking may take place or else they don't wear a helmet.

- The vehicle can be turned on and stolen by bypassing the ignition switch.

\section{Literature Survey}

Sudarshan Raj, Manjesh N has proposed a Smart Helmet using GSM \& GPS Technology for Accident Detection and Reporting System, International Journal of Electrical and Electronics Research [1]. Abhinav Anand, Alcoholic detection. It is an alcoholic sensor used to find the alcohol content in the breath [2]. Mohd Khairul, Smart Helmet with sensors for accident prevention, the GSM and GPS are used to find and locate the rider [3] [4]. A. Bhargav Aditya and K. Bharath, Smarttec Helmet.

Still the riders do not obey the rules. These accidents are caused due to the negligence of the rider [5]. Every country has assigned a law that enforcing their citizen to wear a helmet while riding in the bike and not to ride a bike when the rider is under the influence of alcohol, but still rules are being violated [6] [7]. Intelligent safety helmet for the motorcyclist and it consists of an intelligent system embedded into the helmet and the vehicle. Helmet unit ensures that the bike rider is wearing a helmet and if under the influence of alcohol, the vehicle unit will not start. It communicates with the vehicle unit to switch off the ignition system of the bike if the above condition is not met [8] [9]. Design of Intelligent Helmet to Prevent Bike Accident in India, which able to support accident avoidance and theft-proof [10] [11]. 


\section{Proposed System}

This system briefly explains the implementation of the smart helmet and components used in it. The components used are FSR, MQ-3, vibrating sensors, LED strips, NodeMCU, 4channel relay, cloud. The FSR (force sensing resistor) is used to sense, if the rider wears the helmet, only then the motor will start or else the motor will fail to start. The MQ-3 (Mingan Qilai-3) is an alcoholic sensor if the rider consumed alcohol which is more than $0.04 \mathrm{mg} / \mathrm{l}$ in breath then the driver can't drive the bike. These two sensors satisfy this condition only the ignition of the motor will start or else it doesn't start. They connected to the NodeMCU, which is a wifi module configured to communicate with the bike unit. The vibrating sensor (piezoelectric sensor) when a range of frequency generated by the vibrating sensor depending upon vibration produced due to accident or obstacle. If the frequency is maximum than the threshold value then the bike unit shows the accident detected. This also configured with NodeMCU. Then the channel relay is used to connect the ignition of the motor, led indication strips. Once, bike unit shows that the Accident Detected then NodeMCU sends the location request to the cloud storage (ubidots) and the coordinates of the location are sent back to the NodeMCU to concerned mobile number or email. It sends latitude and longitude to already saved sim numbers. LED strips are used for left, right, the brake of the indication.

\section{Advantages:}

- It is a smart helmet which helps to control the ignition on and off.

- MQ-3 sensor used to find whether the riders are alcohol consumed or not.

- LED strips used in this helmet to indicate the presence of the rider and it is very useful to bike riders in the night.

- It detects fall detection by using a vibrating sensor.

- This smart helmet helps to Locate the bike and rider in accident cases.

\section{System Design}

This system design mainly focuses on two modules that is user and admin module. The user module is an interactive module where the helmet unit sends and communicates with the rider. The admin module is used to receive and respond to the helmet unit.

\section{A. Helmet unit B. Bike unit}

\section{A. Helmet Unit:}

This helmet unit (figure 1) consists of a force sensing resistor, MQ-3 sensor, vibrating sensor, NodeMCU, relay driver, led strips.

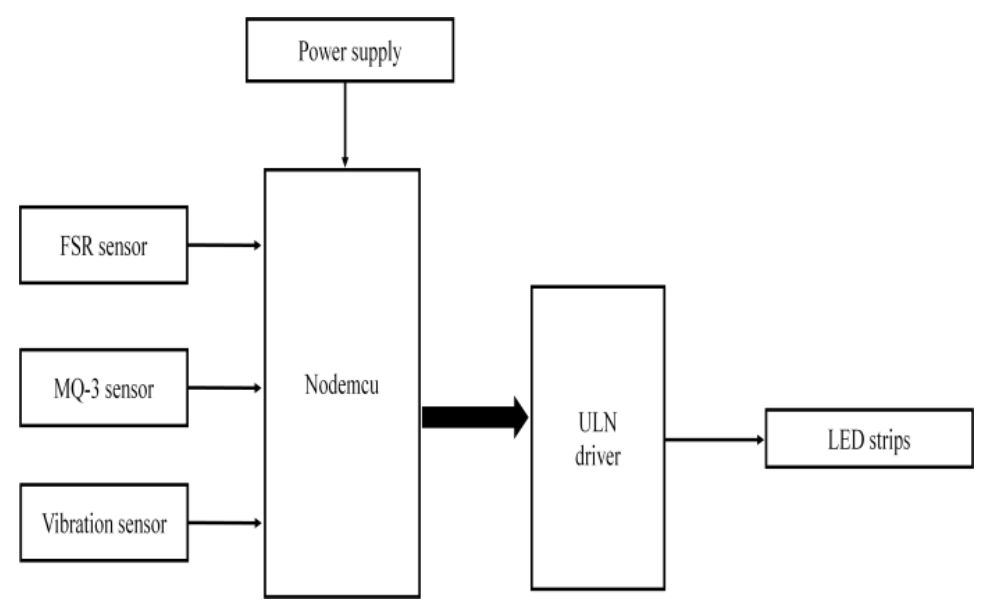

Figure 1. Helmet Unit 
These three sensors are implanted in the helmet unit. The sensors read the input value of the rider and using NodeMCU it transfers the data to the bike unit. Led strips are used to provide a signal sign of the bike indication through the helmet unit. We are using relay driver for power shifting to the led strips.

\section{B. Bike Unit}

The bike unit (figure 2) consists of switch s1, s2, s3, NodeMCU, relay driver, motor, cloud. These three switches s1, s2, s3 are used for the indication switches for the led strips in the helmet unit. Then the relay driver is used to drive the motor with the help of the NodeMCU. If the helmet unit sends an accident detected then the bike unit sends the data to the cloud. Then the emergency message has been transmitted to the concerned mobile numbers.

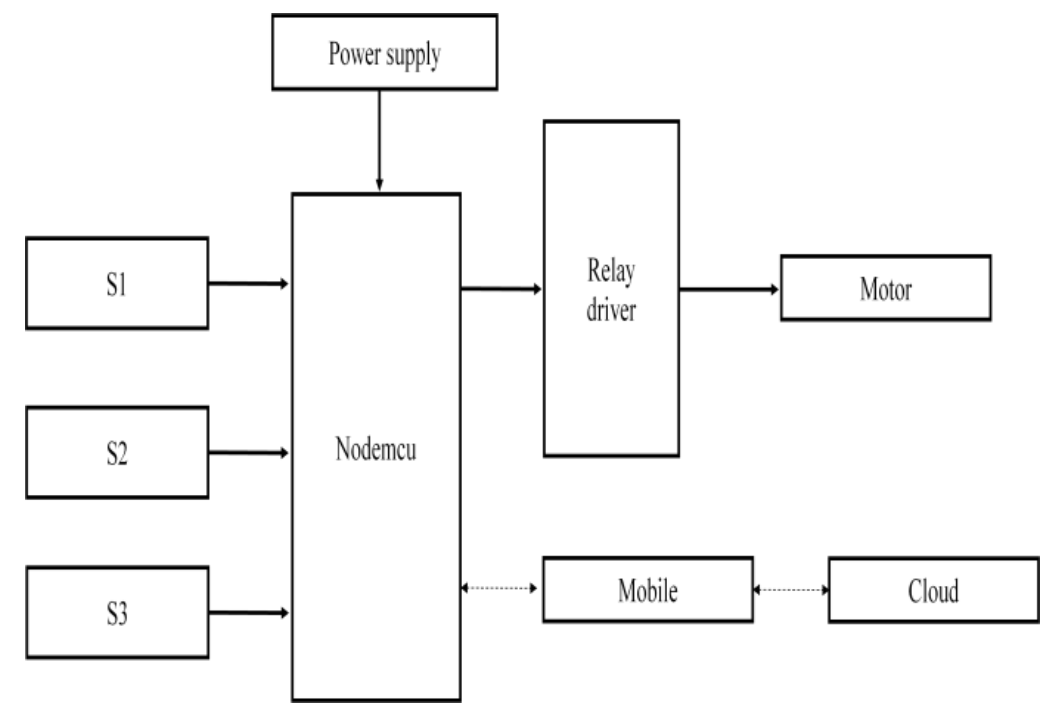

Figure 2. Bike Unit

\section{Materials and Implementations}

1) FSR: The FSR (force sensing resistor) is used to sense the physical pressure, squeezing. Their power consumption is less. They are used for most touch sensitive applications. They are low cost and less weight. This sensor (figure 3) is configured with the NodeMCU, then the data is being transmitted to the cloud.

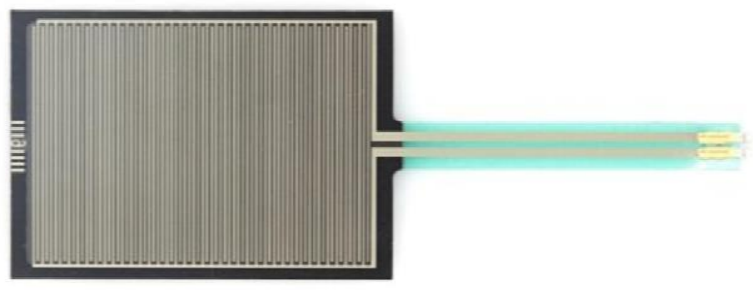

Figure 3. FSR Sensor

2) MQ-3: The MQ-3 (Mingan Qilai-3) is an alcoholic sensor, it is a low-cost semiconductor sensor which can detect the alcohol presence in the air at a concentration from $0.05 \mathrm{mg} / 1$ to 10 
$\mathrm{mg} / \mathrm{l}$. It is constructed by a sensitive material called Sno2. This sensor is configured with the NodeMCU, then the data is being transmitted to the cloud. As shown in figure 4.

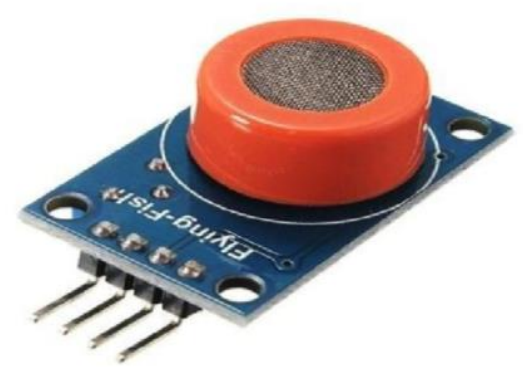

Figure 4. MQ-3 Sensor

3) Vibrating sensor: The vibrating sensor (figure 5) is also called a piezoelectric sensor, when a range of frequency generated by the vibrating sensor depending upon vibration it can measure the pressure, temperature, acceleration, force. It measures the force and damped vibration. This sensor is configured with the NodeMCU, then the data is being transmitted to the cloud.

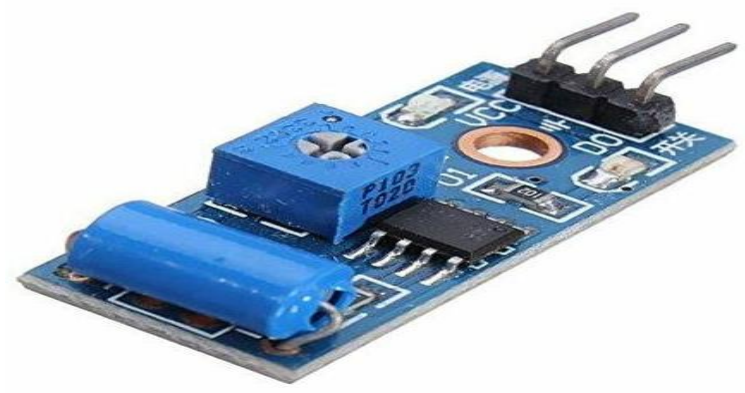

Figure 5. Vibrating Sensor

4) NodeMCU: NodeMCU (figure 6) is a low-cost module, it is also named as ESP8266 WIFI SOC. It specifies as a WIFI module for communication between the nodes, which is based on the ESP-12 module. NodeMCU can store more code compared to UNO. It plays a major part in the communication platform.

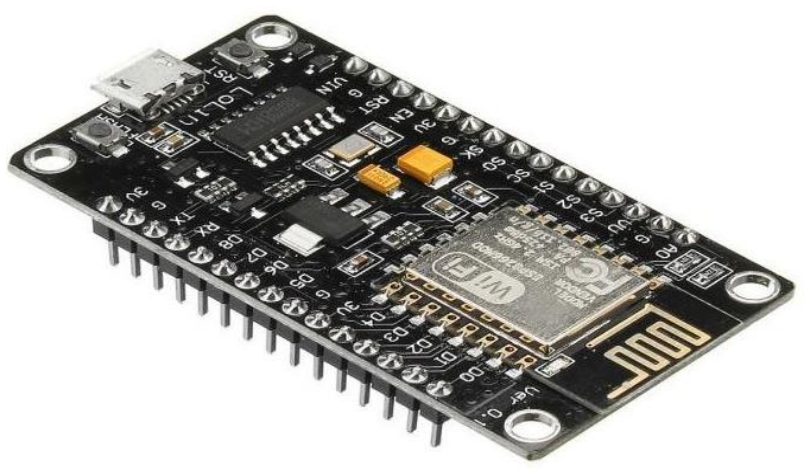

Figure 6. NodeMCU 
5) Relay Driver: A relay driver (figure 7) is an electromagnetic switch used to produce a low voltage circuit, which is capable of lighting a bulb on and off. It can handle the 220v mains supply. There are various ways to drive a relays Ics. It used to drive a bulb, motor, fan, etc.

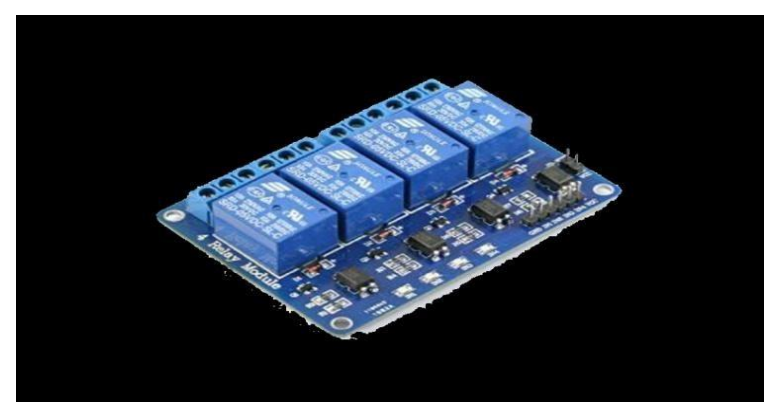

Figure 7. Relay driver

6) LED Strips: The led strips (figure 8) are used to be flexible circuit board, they are printed circuit boards they are welded together. RGB LED consists of 3 small LEDs as red, green, blue. They can produce any color significantly. It is also called a Surface mount led.

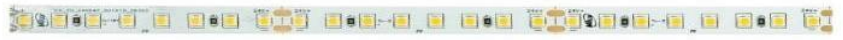

Figure 8. LED Strips

7) Cloud: The ubidots (figure 9) is cloud storage used to provide storage space to turn sensor data into information data. This data can be used to analyze the educational research and machine to machine interactions. We can build any type of application over the IoT platform.

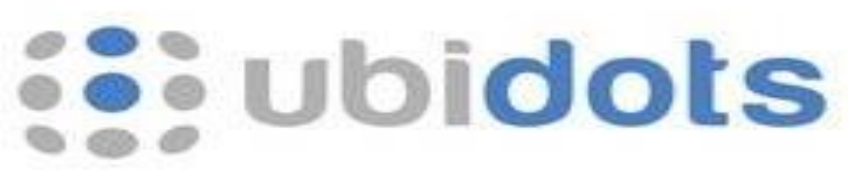

Figure 9. Cloud (ubidots)

\section{Results}

The proposed system is implemented by using the NodeMCU and cloud. We have successfully implemented both helmet and bike unit. The helmet unit is connected with the bike unit with the help of NodeMCU and it helps to detect or locate the accident spot accurately. As show in figure $(10,11,12,13)$.

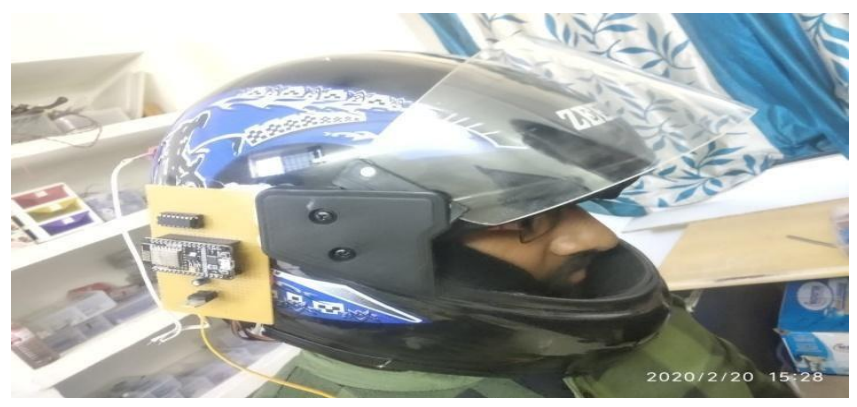

Figure 10. Helmet Unit (side view) 


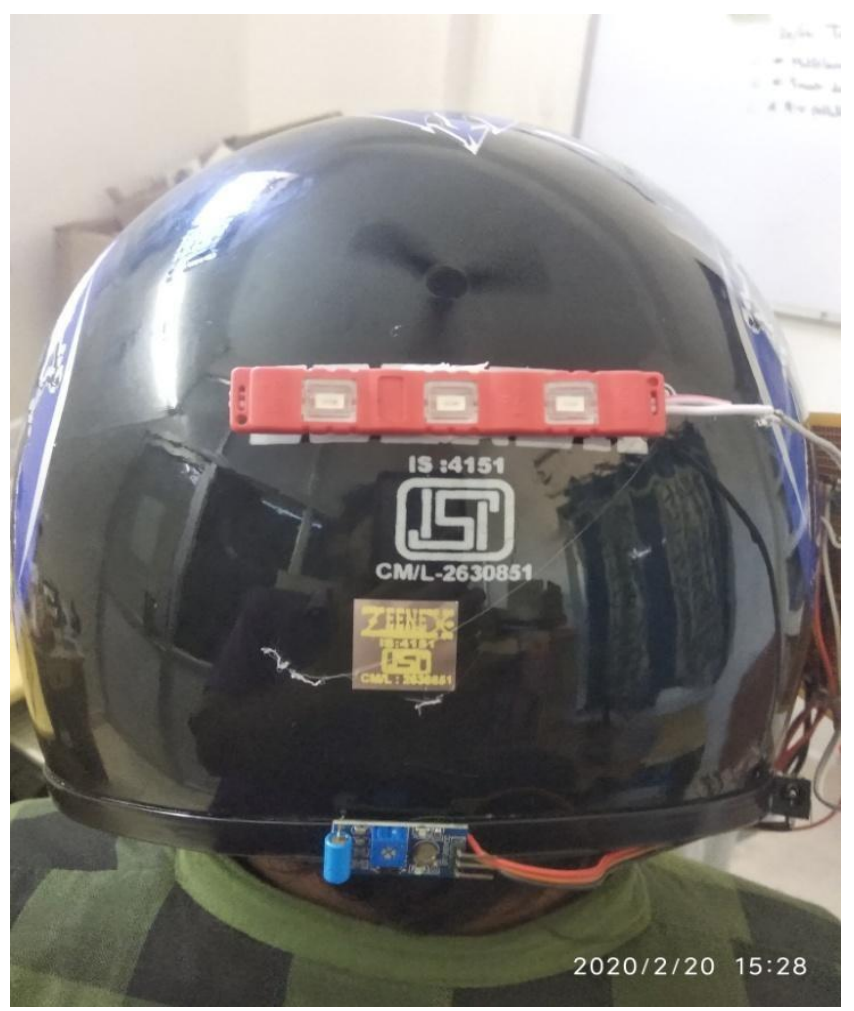

Figure 11. Helmet Unit (back view)

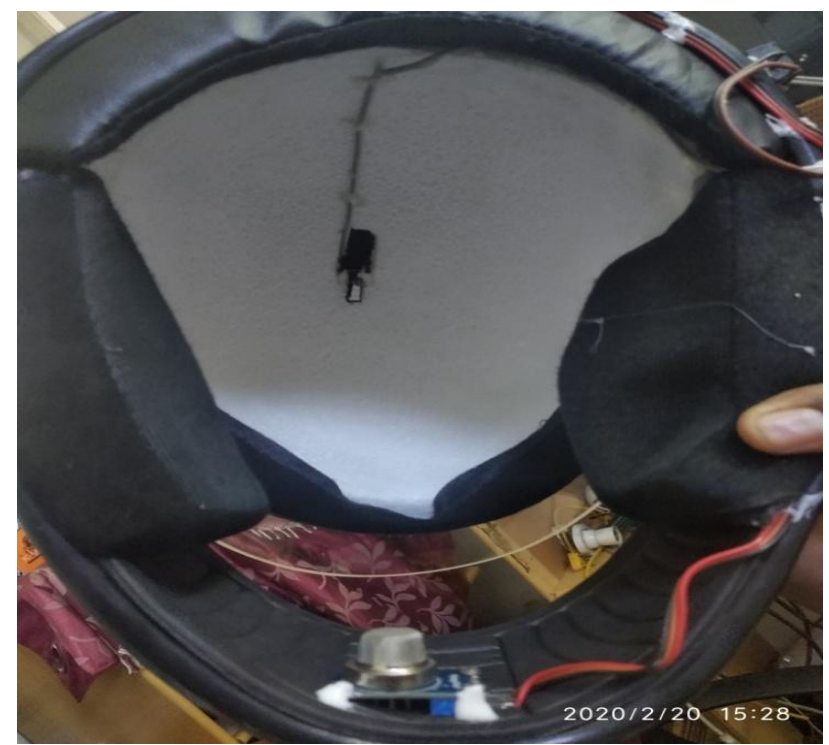

Figure 12. Helmet Unit (inner view)

$<\quad$ emergency 


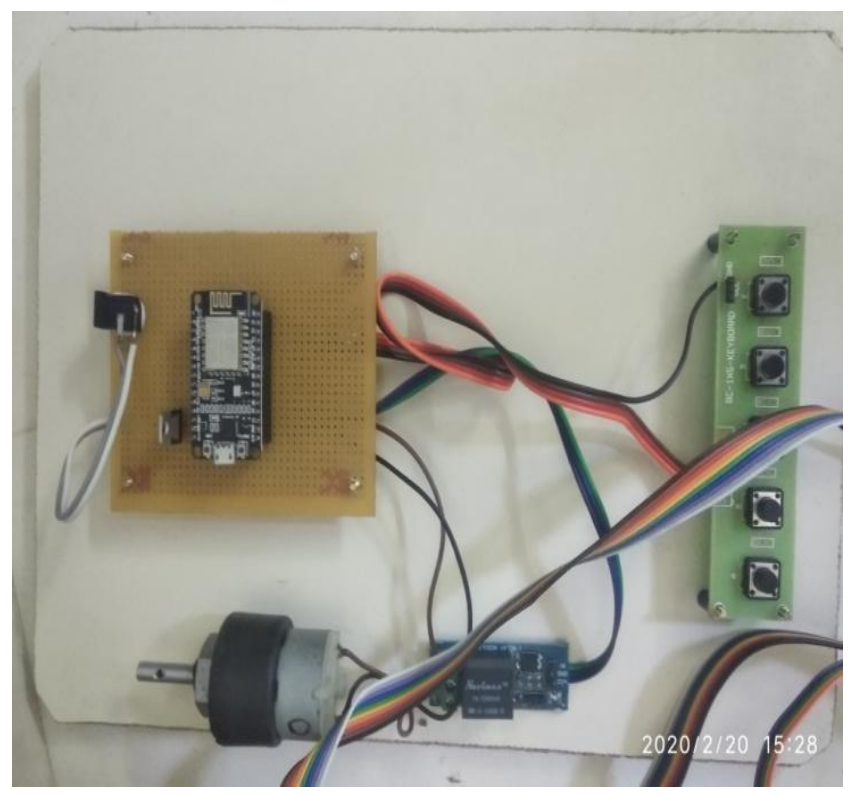

Figure 14. Bike Unit

\section{Conclusion and Future Works}

This smart safety helmet enables users to control the bike unit easily, it reduces the nuisance caused by a drunken driver. Also, it adds on to the preventing of any unwanted accidents that happen due to alcohol consumption or due to the negligence of helmet by the rider. It acts as a safety measure to the rider; it significantly reduces the accident possibilities. The user has to wear a helmet to ride the vehicle, and hence, traffic rules will follow with this. This system is under pocket control, i.e., The two-wheeled vehicle having safety and, in the budget, also. This easy and efficient functioning system provides better safety and security to the riders.

\section{Future Enhancement}

Besides the research is concentrated on the avoidance of the accident and proposing a system to follow the rules. For further improvement, we can include the speed and distance calculation before the met of the accident. Then to predict the navigation using the helmet and controlling the acceleration, braking, headlights, storage locking system. We can add the speed control mechanism in a bike and displaying the speedometer value in the helmet. Then include an additional feature as a digital sign and message board. Thereby we can improve the efficiency of bike automation and reduce the accident rate efficiently.

\section{References}

[1] N. Manjesh., Sudarshan Raj, Smart Helmet using GSM \& GPS Technology for Accident detection and Reporting System, International Journal of Electrical and Electronics Research, 2 (2014) 122-127.

[2] Abhinav Anand, Alcoholic detection, Department of Electronics and Telecommunications, IJEETC, 2015.

[3] M. K. A. M. Rasli, N. K. Madzhi, J. Johari, (2013) Smart Helmet with Sensors for Accident Prevention, In 2013 International Conference on Electrical, Electronics and System Engineering (ICEESE), IEEE, 21-26.

[4] V. Krishna Chaitanya, K. Praveen Kumar, (2013) Smart helmet using arduino, Hyderabad,

[5] R. Prudhvi Raj, Ch. Sri Krishna Kanth, A. Bhargav Aditya, K. Bharath, Smart tec Helmet, Advance in Electronic and Electric Engineering, 4 (2014) 493-498, 
[6] National Crime Records Bureau, Accidental deaths and suicides in India, New Delhi: Ministry of Home Affairs, Government of India; 2005.

[7] Sudharsana Vijayan, Vineed T Govind, Merin Mathews, Simna Surendran, Muhammed Sabah, Alcohol Detection Using Smart Helmet System, International Journal of Emerging Technology in Computer Science \& Electronics, 8 (2014) 190.

[8] Faezah Binti Hashim, (2011) Intelligent Safety Helmet for Motorcyclist, Project report for Bachelors Degree in Electrical Engineering at the Universiti Teknikal, Malaysia Melaka, 124.

[9] J. Vijay, B. Sarith, B. Priyadarshini, S. Deepeka, R. Laxmi, Drunken Drive Protection System, International Journal of Scientific \& Engineering Research 2 (2011) 1-4.

[10] Harish Chandra Mohandas, Raja Kumar Mahapatra, Jyotirmayee Muduli, Anti-Theft Mechanism System with Accidental Avoidance and Cabin Safety System for Automobiles, International Refereed Journal of Engineering and Science (IRJES), 3 (2014) 56-62.

[11] A. Das, S. Goswami, P. Das, [2015] Design and Implementation of Intelligent Helmet to Prevent Bike Accident in India, In 2015 Annual IEEE India Conference (INDICON), IEEE, $1-6$.

[12] S. Vijayan, V.T. Govind, M. Mathews, S. Surendra, Alcohol Detection Using Smart Helmet System, International Journal of Emerging Technology in Computer Science and Electronics, 81 (2014) 190.

[13] J. Vijay, B. Saritha, B. Priyadharshini, S. Deepeka, R. Laxmi, Drunken Drive Protection System, International Journal of Scientific \& Engineering Research, 2 (2011)1-4.

[14] S. P. Bhumkar, V. V. Deotare, R.V. Babar, Accident Avoidance and Detection on Highways, International Journal of Engineering Trends and Technology, 3 (2012) 247-252.

[15] K. Sudarsan, P. Kumaraguru Diderot, Helmet for Road Hazard Warning with Wireless Bike Authentication and Traffic Adaptive Mp3 Playback, International Journal of Science and Research (IJSR), 3 (2014) 340-345.

[16] M. Penta, M. Jadhav, P. Girme, Bike Rider's Safety Using Helmet, International Journal of Electrical and Electronic Engineering \& Telecommunications, 4 (2015) 37-44.

[17] N. James, C. Aparna, T. P. John, Alcohol Detection System, International Journal of Communication and Computer Technologies, 3 (2014) 59-64.

[18] R. Nazir, A. Tariq, S. Murawwat, S. Rabbani, Accident Prevention and Reporting System Using GSM (SIM 900D) And GPS (NMEA 0183), International Journal Communications, Network and System Sciences, 7 (2014) 286-293.

[19] E.D. Bekiaris, A. Spadoni, S.I. Nikolaou, (2009) New Safety and Comfort in Powered Two Wheelers, In 2009 2nd Conference on Human System Interactions, IEEE, 600-602.

[20] M. Pieve, F. Tesauri, A. Spadoni, (2009) Mitigation Accident Risk in Powered Two Wheelers: Improving Effectiveness of Human Machine Interface Collision Avoidance System in Two Wheelers, In 2009 2nd Conference on Human System Interactions, IEEE, 603-607.

[21] Orace, V.S. Reinhardt, S.A Vanghn, Integrated disease Surveillance Project -Project Implementation plan, (2004).

[22] Ping Li, Ramy Meziane, J.D. Martin. Otis, Hassan Ezzaidi, (2014) A Smart Safety Helmet Using IMU and EEG Sensors for Worker Fatigue Detection, In 2014 IEEE International Symposium on Robotic and Sensors Environments (ROSE) Proceedings, IEEE, 55-60

[23] Pratiksha Bhuta, Karan Desai, Archita Keni, Alcohol Detection and Vehicle Controlling, International Journal of Engineering Trends and Applications (IJETA), 2 (2015) 92-97. 
[24] K. Sudarsan, P. Kumaraguru Diderot, Helmet for Road Hazard Warning with Wireless Bike Authentication and Traffic Adaptive Mp3 Playback, International Journal of Science and Research (IJSR), 3 (2014) 340-345.

[25] N. Manjesh, C. H. Sudarshan raju, (2015) Safety measures for Two wheelers by Smart Helmet and Four wheelers by Vehicular Communication, In National Conference on Developments, Advances And Trends In Engineering Sciences and International Journal of Engineering Research and Applications (IJERA), 15-19.

\section{Acknowledgement Nil}

\section{Funding}

This study was not funded by any grant

\section{Conflict of interest}

None of the authors have any conflicts of interest to declare.

\section{About The License}

The text of this article is licensed under a Creative Commons Attribution 4.0 International License

\section{Cite this Article}

P. Dharani, T. Ganesh, V. Gopinath, Y. Sharmasth Vali, Smart Safety Helmet for Bike Riders using IoT, International Research Journal of Multidisciplinary Technovation, Vol 2, Iss 4(2020) 21-30.

DOI: https://doi.org/10.34256/irimt2044 